\title{
Hepatocyte Growth Factor Induces Retinal Vascular Permeability via MAP-Kinase and PI-3 Kinase without Altering Retinal Hemodynamics
}

\section{Citation}

Clermont, Allen C., Mark Cahill, Haytham Salti, Susan L. Rook, Christian Rask-Madsen, Lucy Goddard, Jun S. Wong, Dahlia Bursell, Sven E. Bursell, and Lloyd Paul Aiello. 2006. Hepatocyte Growth Factor Induces Retinal Vascular Permeability via MAP-Kinase and PI-3 Kinase Without Altering Retinal Hemodynamics. Invest. Ophthalmol. Vis. Sci. 47, no. 6: 2701. doi:10.1167/ iovs.05-0071.

\section{Published Version}

doi:10.1167/iovs.05-0071

\section{Permanent link}

http://nrs.harvard.edu/urn-3:HUL.InstRepos:33776274

\section{Terms of Use}

This article was downloaded from Harvard University's DASH repository, and is made available under the terms and conditions applicable to Other Posted Material, as set forth at http:// nrs.harvard.edu/urn-3:HUL.InstRepos:dash.current.terms-of-use\#LAA

\section{Share Your Story}

The Harvard community has made this article openly available.

Please share how this access benefits you. Submit a story.

Accessibility 


\title{
Hepatocyte Growth Factor Induces Retinal Vascular Permeability via MAP-Kinase and PI-3 Kinase without Altering Retinal Hemodynamics
}

\author{
Allen C. Clermont, ${ }^{1}$ Mark Cabill, ${ }^{2}$ Haytham Salti, ${ }^{3}$ Susan L. Rook, ${ }^{1}$ \\ Christian Rask-Madsen, ${ }^{1}$ Lucy Goddard, ${ }^{1}$ Jun S. Wong, ${ }^{4}$ Dablia Bursell, ${ }^{1}$ Sven E. Bursell, ${ }^{1}$ \\ and Lloyd Paul Aiello ${ }^{1,5}$
}

Purpose. Although vascular endothelial growth factor (VEGF) is a key mediator of retinal vascular permeability (RVP), there may be additional humoral contributors. Hepatocyte growth factor (HGF) induces endothelial cell separation, regulates expression of cell adhesion molecules and is increased in the vitreous fluid of patients with proliferative diabetic retinopathy. The purpose of this study was to evaluate the in vivo effects of HGF on RVP and retinal hemodynamics and delineate the signaling pathways.

Methods. RVP was assessed by vitreous fluorescein fluorophotometry in rats. Time course and dose-response were determined after intravitreal HGF injection. MAP kinase (MAPK), phosphatidylinositol 3-kinase (PI-3 kinase), and protein kinase $\mathrm{C}$ (PKC) involvement were examined by using selective inhibitors. Retinal blood flow (RBF) and mean circulation time (MCT) were evaluated by video fluorescein angiography.

Results. HGF increased RVP in a time- and dose-dependent manner. HGF-induced RVP was evident 5 minutes after injection, and reached maximal levels after 25 minutes $(+107 \%$ versus vehicle, $P=0.002$ ). This effect was comparable to that of maximum VEGF stimulation $(134 \% \pm 128 \%$ at $25 \mathrm{ng} / \mathrm{mL})$. Selective inhibitors of MAPK (PD98059) and PI-3 kinase (LY294002) suppressed HGF-induced RVP by $86 \% \pm 44 \%(P=$ $0.015)$ and $97 \% \pm 59 \%(P=0.021)$, respectively. Non-isoformselective inhibition of PKC did not significantly decrease HGFinduced RVP. Although VEGF increases RBF and reduces MCT, HGF did not affect either.

Conclusions. HGF increases RVP in a time- and dose-dependent manner at physiologically relevant concentrations with a magnitude and profile similar to that of VEGF, without affecting retinal hemodynamics. Thus, HGF may represent another clinically significant contributor to retinal edema distinct

From the ${ }^{1}$ Section of Eye Research and Beetham Eye Institute, Joslin Diabetes Center, Boston, Massachusetts; the ${ }^{2}$ Duke University Eye Center, Durham, North Carolina; the ${ }^{3}$ Department of Ophthalmology, American University of Beirut Medical Center, Beirut, Lebanon; the ${ }^{4}$ Department of Ophthalmology, Hospital UKM, Jalan Yaacob Latiff, Kuala Lumpur, Malaysia; and the ${ }^{5}$ Department of Ophthalmology, Harvard Medical School, Boston, Massachusetts.

Supported by Massachusetts Lions Eye Research.

Submitted for publication January 20, 2005; revised June 30 and August 12, 2005; accepted April 12, 2006.

Disclosure: A.C. Clermont, None; M. Cahill, None; H. Salti, None; S.L. Rook, None; C. Rask-Madsen, None; L. Goddard, None; J.S. Wong, None; D. Bursell, None; S.E. Bursell, None; L.P. Aiello, None

The publication costs of this article were defrayed in part by page charge payment. This article must therefore be marked "advertisement" in accordance with 18 U.S.C. $\$ 1734$ solely to indicate this fact.

Corresponding author: Lloyd Paul Aiello, Joslin Diabetes Center, One Joslin Place, Boston, MA 02215; 1paiello@joslin.harvard.edu. from the actions of VEGF. (Invest Ophthalmol Vis Sci. 2006; 47:2701-2708) DOI:10.1167/iovs.05-0071

$\mathbf{R}$ etinal vascular leakage is a vision-threatening complication associated with numerous ocular conditions, including diabetic macular edema, retinal vein occlusions, retinopathy of prematurity, and exudative age-related macular degeneration. Various cytokines are thought to mediate these permeability changes. Vascular endothelial growth factor (VEGF), ${ }^{1}$ also referred to as vascular permeability factor (VPF), ${ }^{2}$ is an endothelial cell mitogen with angiogenic and vasopermeability activity thought to play a critical role in this regard. ${ }^{3-8}$ Involvement of additional humoral factors in mediating these complex events is likely, although the contribution of other factors is not fully understood.

Hepatocyte growth factor (HGF), or scatter factor (SF), was originally described as a fibroblast-derived paracrine modulator of epithelial cell mobility.? HGF has a disulfide-linked heterodimer structure comprising a $62-\mathrm{kDa} \alpha$-chain and a $32-\mathrm{kDa}$ $\beta$-chain. ${ }^{10}$ Its biological effects are mediated through the receptor c-MET, a cell surface tyrosine kinase receptor encoded by the c-MET proto-oncogene. ${ }^{11,12}$ The c-MET receptor has been localized at intercellular junctions, and its expression is induced by cytokines, PMA, and HGF itself. ${ }^{13}$ On receptor binding, HGF induces autophosphorylation of the receptor at tyrosine residues in both the kinase region and regulatory carboxyl-terminal tail ${ }^{14}$ resulting in subsequent altered expression of proteins responsible for cell- cell adhesion and eventual separation of endothelial cells at intercellular junctions. ${ }^{15-17}$ Expression of the tight-junction-forming proteins occludin, claudin-1, -2, and -5; JAM-1 and -2; and the cell adhesion molecule cadherin are reduced by HGF ${ }^{17-20}$ HGF increases the association of the adhesion protein complex E-cadherin/catenin with $\mathrm{cMet}^{21}$ resulting in the loss of $\beta$-catenin from the E-cadherin/catenin complex and subsequent decreased cellcell adhesion. $^{22}$

HGF is also a potential mediator of retinal neovascularization, ${ }^{23}$ as evidenced by its mitogenic and motogenic effects on retinal endothelial cells in culture. ${ }^{24-26}$ HGF expression is upregulated under hypoxic conditions, ${ }^{27}$ and its concentration is significantly higher in the vitreous fluid of diabetic patients with active PDR compared with the vitreous fluid of nondiabetic patients, nondiabetic patients with proliferative vitreoretinopathy, diabetic patients without PDR, or diabetic patients with quiescent PDR. ${ }^{28,29}$ In cultured human epidermal keratinocytes, HGF induces VEGF expression. ${ }^{30}$

Studies have demonstrated that retinal endothelial cells express HGF and its receptor. ${ }^{25,26,31}$ HGF induces MAP kinase (MAPK) phosphorylation in bovine retinal endothelial cells in culture, a response partially mediated by phosphatidylinositol 3-kinase (PI-3 kinase) and, to a lesser extent, protein kinase $\mathrm{C}$ (PKC). ${ }^{26}$ The effector protein Grb2 is thought to link downstream mediators with the receptor cMet. ${ }^{32}$ In other cell types, 
HGF signaling may involve PI-3 kinase, ERK, p38 MAPK, PKC, and Rho GTPases. ${ }^{33,34}$

Although previous cell culture and biochemical data suggest that $\mathrm{HGF}$ may act as a regulator of angiogenesis and vasopermeability, the in vivo effect of HGF on retinal vascular permeability and retinal hemodynamics, the magnitude of its effect in relation to known important permeability factors in the eye, and the pathways mediating these effects have not been previously evaluated.

Our results demonstrate that HGF increases retinal vascular permeability in a dose-dependent manner, resulting in ocular permeability at physiologically relevant concentrations similar to that observed for VEGF. Unlike VEGF, however, retinal mean circulation time and blood flow remain unaltered. In addition, inhibition of PI-3 kinase or MAPK, but not PKC, suppresses HGF-induced retinal vascular permeability, suggesting that both PI-3 kinase and MAPK are important in mediating HGF's retinal permeability, whereas the role of PKC may be less significant.

\section{Methods}

\section{Animals}

Male albino Sprague-Dawley rats weighing 200 to $250 \mathrm{~g}$ were obtained from Taconic (Germantown, NY). All animals were treated according to the ARVO Statement for the Use of Animals in Ophthalmic and Vision Research.

\section{Vitreous Fluorescein Fluorophotometry}

The instrumentation for vitreous fluorescein fluorophotometry has been described. ${ }^{3}$ Briefly, the fluorophotometer consists of a modified slit lamp (Haag-Streit, Köniz, Switzerland) which provides both illumination and collection optics. A 488-nm argon laser (Omnichrome, La Jolla, CA) provides the excitation wavelength. Focused onto a fiber optic, the laserlight is delivered to the vitreous under direct visualization. The emitted fluorescence is collected through a fiber optic and delivered to a monochromator (SPEX Industries, Metuchen, NJ). The emitted light is dispersed along an intensified 1024 photodiode array, and the spectra displayed graphically onscreen (Princeton Instruments, Trenton, NJ). Each spectrum is analyzed by determining the ratio of the integrated fluorescence centered at $520 \mathrm{~nm}$ to the intensity of the unshifted laser line. This ratio represents a normalized vitreous fluorescence level with respect to attenuation of both the incident excitation and emitted fluorescence intensities.

Each animal had a 13-cm length of polyvinyl catheter (Renathane MRE-033; Braintree Scientific, Braintree, MA) surgically implanted into the right jugular vein 24 hours before the experiment. The catheter was subcutaneously located along the shoulder for later access from the back of the animal. On the day of the experiment, the fluorophotometer was calibrated with a fluorescent standard. Animals were anesthetized using pentobarbital $(50 \mathrm{mg} / \mathrm{kg})$ and both eyes were dilated with $1 \%$ tropicamide. Background fluorescence spectra were obtained from each animal. The jugular catheter was exposed and connected to a $100-\mu \mathrm{L}$ syringe (Hamilton, Reno, NV) containing $65 \mu \mathrm{L}$ of $10 \%$ sodium fluorescein.

\section{HGF Time Course and Dose Response}

The dose-response and time course of intravitreal HGF injection on in vivo retinal vascular permeability was examined by injecting $10 \mu \mathrm{L}$ of recombinant human HGF (R\&D Systems, Minneapolis, MN) dissolved in filtered $0.1 \%$ bovine serum albumin and phosphate-buffered saline (PBS) into the vitreous of one eye. The final concentration of HGF was calculated based on the vitreous volume, per Hughes. ${ }^{35}$ Intravitreal injections were performed under direct visualization, by using a $10-\mu \mathrm{L}$ syringe (Hamilton) with a 32-gauge needle inserted $2 \mathrm{~mm}$ posterior to the limbus. Contralateral eyes received an intravitreal injection of 10 $\mu \mathrm{L}$ vehicle alone. Sodium fluorescein (65 $\mu \mathrm{L}$ of $10 \%)$ was infused intravenously 10 minutes after HGF injection. As a positive control, 2 $\mathrm{ng}(0.48 \mathrm{nM}$ final) of recombinant human VEGF (R\&D Systems) was injected into the vitreous of one eye in another set of animals. Vitreous fluorophotometry measurements were obtained at 5, 15, and 25 minutes after fluorescein infusion.

For dose-response experiments, HGF was injected into the vitreous of one eye and vehicle into the contralateral eye. Vitreous fluorophotometry measurements were obtained 25 minutes after fluorescein infusion.

\section{HGF Signal Transduction}

A $10-\mu \mathrm{L}$ volume of inhibitors of protein kinase C (GFX; Sigma-Aldrich, St. Louis, MO), MEK (PD98059, $20 \mu \mathrm{M}$ final), or PI-3 kinase (LY294002, $50 \mu \mathrm{M}$ final) was injected into the vitreous of one eye, and vehicle alone was injected into the vitreous of the contralateral eye. After 10 minutes, a $10-\mu \mathrm{L}$ volume containing $5 \mathrm{ng}(0.69 \mathrm{nM}$ final) of HGF was injected into the vitreous of both eyes. After 10 minutes, $65 \mu \mathrm{L}$ of $10 \%$ sodium fluorescein was infused, and vitreous fluorophotometry measurements were obtained 25 minutes later.

\section{Western Blot of In Vivo Retinal HGF-Induced MAPK Activity}

Protein was extracted from rat retinas using RIPA buffer with protease inhibitors. Total protein concentration was determined by protein assay (Bio-Rad, Hercules, CA). Total protein $(50 \mu \mathrm{g})$ was separated by $12 \%$ SDS-PAGE, transferred to nitrocellulose (Bio-Rad), and incubated with phospho-p44/42 MAPK or p42 MAPK primary antibody (Cell Signaling, Beverly, MA) overnight at $4{ }^{\circ} \mathrm{C}$. Proteins were visualized with a chemiluminescence system (GE Healthcare, Piscataway, FL)

\section{Mean Circulation Time and Retinal Blood Flow}

Video fluorescein angiography was used to determine retinal blood Flow (RBF). The video fluorescein angiography system has been described. ${ }^{36}$ Briefly, the system consists of a fundus camera (Nikon, Tokyo, Japan) coupled with a low light-level SIT camera. The NTSC output signal was digitized by a (Targa 2000) frame grabber from Truevision (Indianapolis, IN). The images were digitized at a rate of 30 frames/s with a resolution of $640 \times 480 \times 8$-bit gray scale and stored as a sequential series of TIFF images. Analysis of the digitized angiograms was performed on a frame-by-frame basis with a program written in commercial software (MatLab; The MathWorks, Natick, MA).

The procedure for measurement of RBF has been described. ${ }^{37}$ Animals underwent surgical implantation of a polyvinyl catheter into the right jugular vein. After 24 hours, the eyes were dilated and angiograms obtained by rapidly injection of $5 \mu \mathrm{L}$ of $10 \%$ sodium fluorescein. Analyses of the digitized angiograms were performed as detailed previously. ${ }^{36}$ Dye dilution curves were obtained from the primary arteries and veins at a distance of 1.5 optic disc diameters. The dye dilution curves were fit by a log-normal distribution function and the curve-fit parameters used to determine the mean arterial and venous circulation times. The MCT was defined as the difference between the mean venous and arterial filling times. The diameters of the primary vessels were measured at the defined sample sites by a boundary-crossing algorithm. Segmental RBF was calculated by the sum of the squares of the retinal artery and vein diameters divided by the mean circulation time.

\section{Statistics}

Results are expressed as the mean $\pm \mathrm{SD}$, unless otherwise indicated. Statistical analysis was performed on computer (SigmaStat; SPSS, Chicago, IL). Statistical analysis used the Student's $t$-test to compare quantitative data populations with normal distributions and equal variance. The paired test was used for comparison of eyes from the same animal and the unpaired test was used for interanimal comparisons. The 

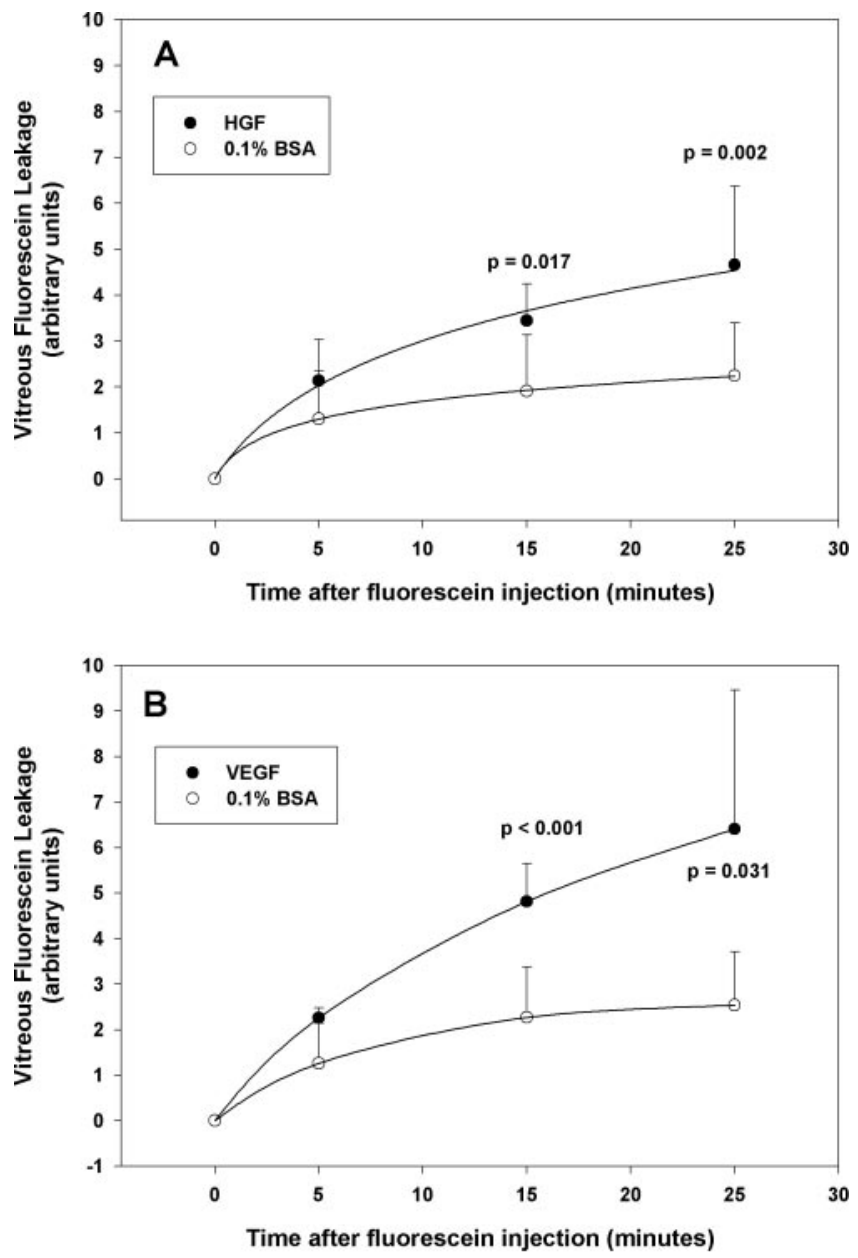

FigURE 1. HGF induces retinal vascular permeability in vivo. Vitreous fluorescein leakage was measured at the indicated times after intravenous fluorescein injection in eyes that had been pretreated for 10 minutes with (A) HGF ( $5 \mathrm{ng} / \mathrm{eye}, 0.69 \mathrm{nM}$ final), (B) VEGF (2 ng/eye, $0.48 \mathrm{nM}$ final), or vehicle control (0.1\% BSA).

Mann-Whitney rank-sum test was used for populations with non-normal distributions or unequal variance.

\section{Results}

\section{Characterization of HGF-Induced Retinal Vascular Permeability}

The effect of HGF on retinal vascular permeability (RVP) in vivo was assessed by vitreous fluorophotometry. HGF (5 ng/ eye, $0.69 \mathrm{nM}$ final) or vehicle alone was injected intravitreally, and 10 minutes later sodium fluorescein was injected intravenously and retinal vascular leakage was assessed after an additional 5, 15, and 25 minutes. In eyes receiving vehicle alone (0.1\% BSA), vitreous fluorescence increased $1.26 \pm 0.87$, $1.91 \pm 1.23$, and $2.25 \pm 1.15 \mathrm{AU}$ after 5,15 , and 25 minutes, respectively (Fig. 1A), consistent with low basal levels of fluorescein leakage from an intact retinal vasculature, as reported previously. ${ }^{3}$ In eyes receiving HGF, vitreous fluorescence increased $2.14 \pm 0.89,3.45 \pm 0.81$, and $4.66 \pm 1.71 \mathrm{AU}$ after 5 , 15, and 25 minutes, respectively. Thus, HGF increased permeability compared with vehicle alone by $62 \% \pm 68 \%, 81 \% \pm 42 \%$ $(P=0.017)$, and $107 \% \pm 76 \%(P=0.002)$ after 5,15 , and 25 minutes, respectively. After 60 minutes, the effect of HGF on permeability had declined to $57 \% \pm 33 \%$ above that of vehicletreated eyes (data not shown).

VEGF is a well-recognized potent mediator of RVP thought to play a central role in ocular conditions associated with vascular leakage. To evaluate the relative magnitude of the HGF response, VEGF-induced RVP was measured under equivalent conditions. VEGF at doses previously shown to provide the maximal effect ( $2 \mathrm{ng} /$ eye, $0.48 \mathrm{nM}$ final $)^{3}$ increased RVP $79 \% \pm$ $17 \%, 99 \% \pm 34 \%(P<0.001)$, and $134 \% \pm 128 \%(P=0.031)$ compared with vehicle response, at 5, 15, and 25 minutes after fluorescein injection, respectively (Fig. 1B). Thus, the magnitude of the HGF-elicited response was $83 \% \pm 89 \%, 64 \% \pm 34 \%$, and $65 \% \pm 46 \%$ of the VEGF maximum stimulatory effect at 5 , 15, and 25 minutes after infusion, respectively. The magnitude of the HGF-induced stimulated retinal leakage was not statistically different from that observed for VEGF at any time point.

\section{HGF Dose Response}

To determine the dose-response of HGF-induced RVP, intravitreal injections of HGF were given in one eye at the concentrations listed in Figure 2, whereas the contralateral eye received vehicle alone. Maximum stimulation by $\mathrm{HGF}$ was observed at $5 \mathrm{ng} / \mathrm{eye}, 0.69 \mathrm{nM}$ final $(4.66 \pm 1.72$ vs. $2.25 \pm$ $1.14 ; P=0.002$ ), yielding a $143 \% \pm 113 \%$ increase in vitreous fluorescein leakage. Permeability was increased, $61 \% \pm 70 \%$, $91 \% \pm 58 \%(P=0.043)$, and $133 \% \pm 131 \%(P=0.036)$ at $\mathrm{HGF}$ doses of $0.05,0.1$, and $1.0 \mathrm{ng} /$ eye $(0.007,0.014$, and 0.140 $\mathrm{nM}$ ), respectively. The half-maximal HGF effect occurred between 0.1 and $1.0 \mathrm{ng}$ /eye $(0.014$ and $0.140 \mathrm{nM})$. In comparison, VEGF at a maximal stimulatory concentration (2 ng/eye, $0.48 \mathrm{nM}$ final) increased vitreous fluorescein leakage by $200 \%$ $\pm 89 \%(7.74 \pm 4.13$ vs. $2.75 \pm 0.76 ; P=0.035$. $)$ The VEGF response was not significantly different from that observed for 1,5 , or $50 \mathrm{ng}$ /eye HGF.

To determine whether the effect on permeability was generalized or more specific to HGF and VEGF, pigment epithelium derived factor (PEDF), a similarly sized endogenous molecule with survival factor and antiangiogenic and antipermeabilty properties, ${ }^{38}$ was injected into the vitreous. A $10-\mu \mathrm{L}$ volume of PEDF (200 ng) was injected intravitreally into one eye, and balanced saline solution into the contralateral eye.

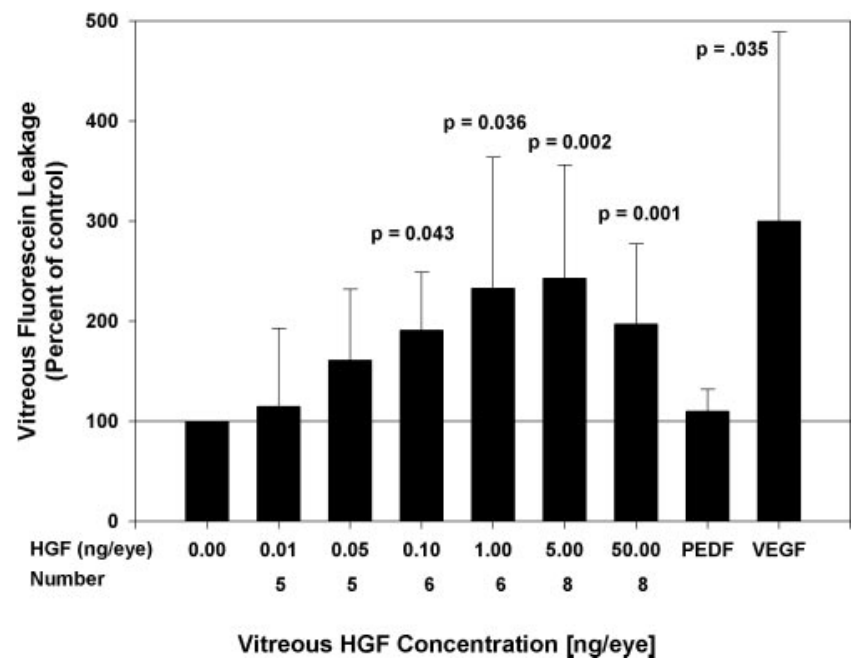

FIGURE 2. HGF increased retinal vascular leakage in vivo at physiologic concentrations and in a dose-dependent manner. Vitreous fluorescein leakage was measured 25 minutes after a 10-minute intravitreal pretreatment with HGF at the concentrations indicated. Retinal vascular leakage after 2 ng/eye VEGF and 200 ng/eye PEDF under maximal effective conditions were also evaluated for comparison. 
As shown in Figure 2, at 25 minutes after fluorescein infusion, no difference was observed in the permeability response for vehicle and PEDF ( $2.35 \pm 0.23$ vs. $2.56 \pm 0.38$, respectively).

\section{HGF Signal Transduction}

To investigate the mechanisms by which HGF stimulates RVP, selective inhibitors of PI-3 kinase (LY294002), protein kinase C (GFX), and MAPK (PD98059) were evaluated. Each of these inhibitors have been used successfully in this animal model. ${ }^{3}$ Inhibitors' concentrations were determined from in vitro experiments with HGF using bovine retinal microvascular endothelial cells. ${ }^{26}$ LY294002 $(0.5$ or $50 \mu \mathrm{M})$ was injected into the vitreous of one eye, and the contralateral eye received vehicle alone. HGF ( $5 \mathrm{ng} /$ eye, $0.69 \mathrm{nM}$ final) was injected into both eyes 10 minutes later. One group of rats received intravitreal injections of PBS in both eyes followed by HGF or BSA (HGF vehicle control). PBS/HGF increased vitreous fluorescein leakage $106 \% \pm 66 \%(4.64 \pm 1.53$ vs. $2.23 \pm 1.12 ; P<0.001)$ compared with PBS/BSA-treated eyes. LY294002, at doses of $0.5(3.08 \pm 0.76, n=8 ; P=\mathrm{NS})$ and $50(2.36 \pm 0.93, n=5)$ $\mu \mathrm{M}$, suppressed HGF-induced RVP by $57 \% \pm 97 \%$ and $96 \% \pm$ $59 \%(P=0.021)$, respectively, compared with the contralateral PBS/HGF-treated eye (Fig. 3).

In additional experiments, intravitreal injection of the MEK specific inhibitor PD98059 $(20 \mu \mathrm{M})$ was performed in one eye and PBS alone performed in the opposite eye. HGF ( $5 \mathrm{ng} /$ eye) was injected into both eyes 10 minutes later. The PBS/HGFtreated eyes increased vitreous fluorescein leakage by $113 \% \pm$ $79 \%$ ( $4.79 \pm 1.78 ; P=0.005)$ compared with PBS/BSA treated eyes. MAPK pathway inhibition suppressed HGF-induced permeability $86 \% \pm 44 \%$ compared with the PBS/HGF-treated eye (Fig. 4A; $P=0.015$ ). To confirm activation of the MAPK pathway by $\mathrm{HGF}$ in vivo, $10 \mathrm{ng} / \mathrm{mL}$ of $\mathrm{HGF}$ was injected intravitreally in one eye and saline control delivered to the contralateral eye. Retinas were excised 5 minutes after intravitreal injection. Intravitreal HGF increased retinal p42/44 ERK phosphorylation by $54 \%$ after 5 minutes compared with contralateral eyes injected with saline control (data not shown). In contrast, intravitreal injection of the non-isoform-selective PKC inhibitor GFX (0.5 $\mu \mathrm{M}$ final) in one eye followed by

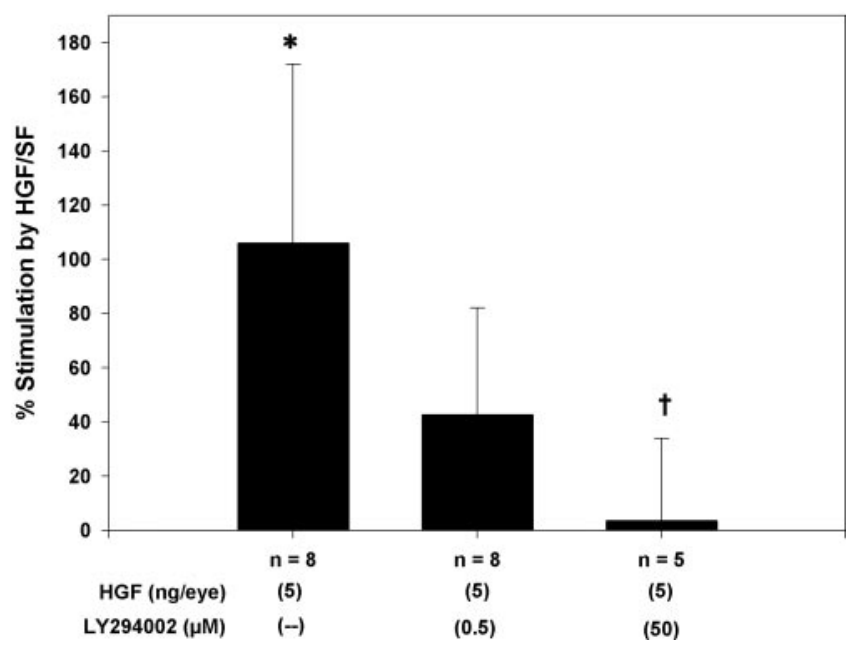

FIGURE 3. HGF-induced retinal vascular permeability was partially mediated by PI-3 kinase in vivo. The effect of HGF injection ( $5 \mathrm{ng} / \mathrm{eye}$ ) on vitreous fluorescein leakage was evaluated after a 10-minute pretreatment with the PI-3 kinase inhibitor LY294002. Pretreatment with vehicle alone followed by HGF injection established basal (100\%) levels. $\left({ }^{*} P=0.005\right.$ compared with eyes pretreated with BSA and injected with BSA, $\dagger P=0.021$ compared with eyes pretreated with BSA and injected with HGF.)
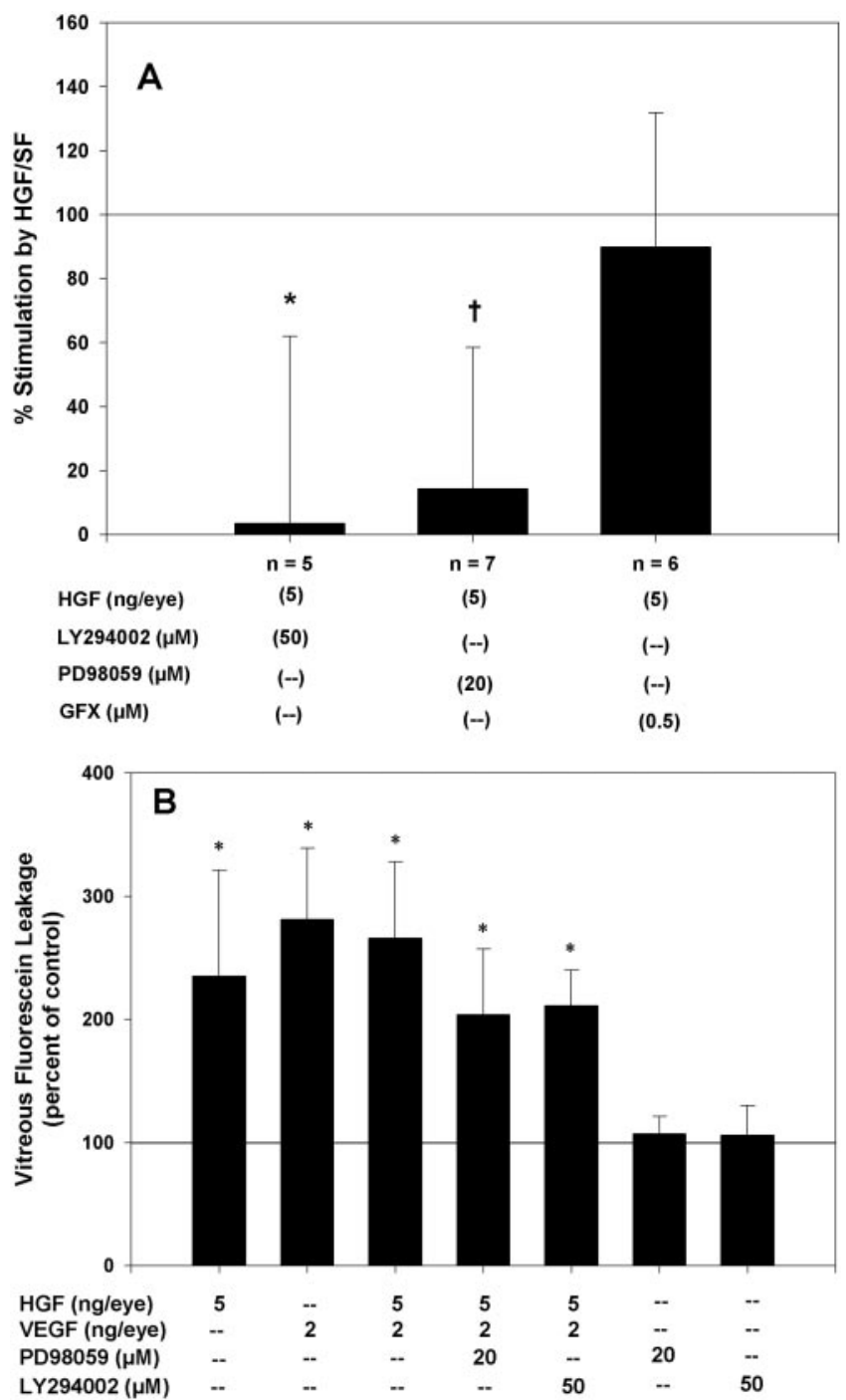

FIGURE 4. (A) HGF-induced retinal vascular permeability was partially mediated in vivo by PI-3 kinase and MAPK, but not by protein kinase C. The effect of a 10-minute pretreatment with PI-3 kinase inhibitor (LY294002 at $50 \mu \mathrm{M}$ ), MEK-specific inhibitor (PD98059 at $20 \mu \mathrm{M}$ ), or non-isoform-selective protein kinase $\mathrm{C}$ inhibitor (GFX at $0.5 \mu \mathrm{M}$ ) on vitreous fluorescein leakage after HGF injection ( $5 \mathrm{ng} / \mathrm{eye}$ ) was evaluated. Pretreatment with BSA established the basal (100\%) HGF/SF leakage stimulation level. ( $P=0.005 ; \dagger P=0.015$ compared with eyes pretreated with BSA and injected with HGF.) (B) HGF/VEGF's effect on retinal vascular permeability was not additive in vivo. The effect of a 10-minute pretreatment with PI-3 kinase inhibitor (LY294002 at 50 $\mu \mathrm{M})$ or MEK-specific inhibitor (PD98059 at $20 \mu \mathrm{M}$ ) on vitreous fluorescein leakage after an HGF ( $5 \mathrm{ng} / \mathrm{eye}) / \mathrm{VEGF}$ ( 2 ng/eye) combination injection was evaluated. Pretreatment with balanced saline established basal $(100 \%)$ leakage stimulation level. ( ${ }^{*} P<0.01$ compared with eyes pretreated with balanced saline and injected with BSA.)

injections of $5 \mathrm{ng}$ /eye HGF after 10 minutes did not significantly reduce retinal leakage $(10 \% \pm 42 \%, P=\mathrm{NS})$ compared with the opposite eye receiving PBS/HGF. GFX used in this manner and at this concentration has been shown to reduce VEGF-induced RVP by $98 \%{ }^{3}$

To evaluate whether the retinal permeability effects of HGF and VEGF were additive, a $10-\mu \mathrm{L}$ volume containing both HGF (5 ng/eye) and VEGF ( $2 \mathrm{ng} /$ eye) was injected into the vitreous of one eye and a $10-\mu \mathrm{L}$ volume of $0.1 \%$ BSA into the contralateral eye. Each eye had been pretreated for 10 minutes by intravitreal injection of balanced saline, the MAPK inhibitor 
TABLE 1. Circulation Parameters with the Three Study Treatments

\begin{tabular}{ccccc}
\hline $\begin{array}{c}\text { Time after Injection } \\
\text { (min) }\end{array}$ & $\begin{array}{c}\text { MCT } \\
(\mathbf{s})\end{array}$ & $\begin{array}{c}\text { Artery Diam. } \\
\text { (pixels) }\end{array}$ & $\begin{array}{c}\text { Vein Diam. } \\
\text { (pixels) }\end{array}$ & $\begin{array}{c}\text { RBF } \\
\text { (pixels squared/s) }\end{array}$ \\
\hline $\begin{array}{l}\text { HGF/SF }(5 \mathrm{ng} / \mathrm{eye}) \\
0\end{array}$ & $0.86 \pm 0.11$ & $5.8 \pm 0.1$ & $6.9 \pm 0.3$ & $96 \pm 15$ \\
5 & $0.89 \pm 0.13$ & $5.8 \pm 0.2$ & $7.0 \pm 0.4$ & $96 \pm 19$ \\
15 & $0.90 \pm 0.10$ & $5.8 \pm 0.2$ & $7.0 \pm 0.4$ & $94 \pm 10$ \\
VEGF (2 ng/eye) & & & & \\
0 & $0.83 \pm 0.09$ & $5.8 \pm 0.1$ & $6.7 \pm 0.5$ & $97 \pm 17$ \\
5 & $0.69 \pm 0.08^{*}$ & $5.9 \pm 0.2$ & $7.2 \pm 0.5$ & $124 \pm 21^{*}$ \\
15 & $0.67 \pm 0.08^{*}$ & $5.6 \pm 0.3$ & $7.1 \pm 0.5$ & $123 \pm 12^{*}$ \\
Vehicle (0.1\% BSA) & & & & \\
0 & $0.87 \pm 0.19$ & $5.9 \pm 0.1$ & $7.1 \pm 0.1$ & $102 \pm 25$ \\
5 & $0.85 \pm 0.13$ & $5.9 \pm 0.1$ & $7.0 \pm 0.2$ & $102 \pm 17$ \\
15 & $0.86 \pm 0.05$ & $5.9 \pm 0.1$ & $7.2 \pm 0.2$ & $101 \pm 6$ \\
\hline
\end{tabular}

MCT, arterial and venous diameters, and RBF were unchanged in rats treated with intravitreous injection of HGF, compared with those treated with vehicle alone. MCT decreased and RBF increased in rats treated with VEGF, when compared with those treated with vehicle. ${ }^{*} P<0.05$ compared with baseline. Diam., diameter.

PD98059 at $20 \mu \mathrm{M}$, or the PI-3 kinase inhibitor LY294002 at 50 $\mu \mathrm{M}$. Balanced saline/HGF- and balanced saline/VEGF-treated eyes increased vitreous fluorescein leakage by $135 \% \pm 86 \%$ $(P=0.004)$ and $182 \% \pm 58 \%(P<0.001)$, respectively compared with balanced saline/BSA-treated eyes (Fig. 4B). Eyes treated with balanced saline and combined HGF/VEGF increased vitreous leakage by $166 \% \pm 61 \%(P=0.041, n=6)$. The combined HGF/VEGF effect was reduced by $37 \% \pm 32 \%(n$ $=6)$ with pretreatment by PD98059 and 33\% $\pm 17 \%(n=5)$ by LY294002, but remained significantly elevated $(P<0.01)$ compared with the response of balanced saline/BSA-treated eyes. Treatment with saline followed by either PD98059 or LY294002 had no effect on basal leakage.

\section{Retinal Blood Flow}

VEGF increases RBF, a physiologic abnormality observed in diabetic patients with more established stages of diabetic retinopathy. ${ }^{42}$ To evaluate whether HGF also affects RBF, video fluorescein angiography (VFA) was performed on rats receiving maximally effective intravitreal injections of HGF ( $5 \mathrm{ng} / \mathrm{eye}$, five rats), VEGF (2 ng/eye, seven rats), and vehicle alone (six rats) as shown in Table 1 . VFA measurements were made at 5 and 15 minutes after the intravitreal injections. Baseline MCT was equivalent between all groups $(0.87 \pm 0.19,0.83 \pm 0.0 .09$, and $0.86 \pm 0.11$ for HGF, VEGF, and vehicle treated groups, respectively). Primary artery and vein diameters, MCT, and RBF were not altered by injection of vehicle alone or HGF (Table 1). In contrast, VEGF treatment reduced MCT $17 \% \pm 10 \%(P=$ $0.004)$ and $19 \% \pm 10 \%(P=0.01$; Fig. $5 \mathrm{~A})$ and increased $\mathrm{RBF}$ by $28 \% \pm 22 \%(P=0.004)$ and $27 \% \pm 13 \%(P<0.001 ;$ Fig. $5 \mathrm{~B})$ after 5 and 15 minutes, respectively. No differences were observed in the primary artery and vein diameters after intravitreal VEGF injection (Table 1).

\section{Discussion}

Numerous ocular disorders result in a vision-threatening increase in RVP, presumably mediated by various cytokines. Studies have demonstrated that retinal endothelial cells express HGF and its receptor c-MET. ${ }^{25-27}$ HGF causes endothelial cell separation, ${ }^{15,16}$ an effect credited to its decreasing occluding tight junction protein ${ }^{18}$ and the cell adhesion molecule cadherin. ${ }^{19}$ In addition, HGF has been shown to decrease transendothelial resistance and increase paracellular permeability in HUVEC monolayers, ${ }^{18,39}$ breast cancer cells, ${ }^{17}$ and mammalian renal epithelial cells. ${ }^{20}$ This effect is associated with a decrease in the expression of the cytoplasmic plaque protein ZO-1, and several tight junction molecules including claudin-1, 2, and 5; occludin; and JAM-1 and $-2 .^{17,20,39}$ These findings suggest that HGF could induce RVP.

To our knowledge, the present studies are the first direct demonstration of HGF-induced retinal permeability in vivo and the first to demonstrate that this effect is of a magnitude similar to that induced by VEGF. Combined with data showing that HGF expression is upregulated under hypoxic conditions, ${ }^{27}$ vitreous and serum concentrations are higher in eyes of patients with proliferative diabetic retinopathy than in patients with nondiabetic diseases, ${ }^{28,29,40}$ and that photocoagulation decreases HGF expression, ${ }^{41}$ these results strongly suggest that HGF may contribute to the retinal vascular leakage characteristic of ocular disorders such as diabetic macular edema. These effects would be in addition to its potential contribution to retinal neovascularization, ${ }^{23}$ as suggested by the mitogenic and motogenic effects on retinal endothelial cells. ${ }^{24-26}$

We demonstrated that HGF induced RVP at concentrations as low as $0.1 \mathrm{ng} / \mathrm{eye}(0.8 \mathrm{ng} / \mathrm{mL} ; P=0.043)$ with a maximum stimulatory concentration of $5 \mathrm{ng} /$ eye $(41.6 \mathrm{ng} / \mathrm{mL} ; P=0.002)$. From Figure 2, the half-maximal stimulatory concentration of $\mathrm{HGF}$ is approximately $0.3 \mathrm{ng} /$ eye $(6.6 \mathrm{ng} / \mathrm{mL})$. Patients with active proliferative diabetic retinopathy have HGF serum concentrations of $0.213 \mathrm{ng} / \mathrm{mL}$ compared with $0.04 \mathrm{ng} / \mathrm{mL}$ for diabetic patients with quiescent retinopathy or patients with no diabetic retinopathy. Seventy percent of patients had serum HGF concentrations higher than $0.1 \mathrm{ng} / \mathrm{mL} .{ }^{40} \mathrm{HGF}$ concentrations in the vitreous are much higher on average $(6.0 \mathrm{ng} /$ $\mathrm{mL}),{ }^{28,29}$ achieving concentrations as high as $22.2 \mathrm{ng} / \mathrm{mL}$ in some patients with PDR. ${ }^{28}$ Our data suggest that these concentrations could easily elicit retinal permeability regardless of contributions from the serum through any preexisting diabetes-induced alterations of the blood-retinal barrier.

Growth factors such as VEGF increase RBF, a physiologic abnormality in diabetic patients associated with advancing stages of diabetic retinopathy. ${ }^{41,42}$ The present study confirmed that VEGF alters retinal MCT and RBF. ${ }^{42}$ However, unlike VEGF, HGF did not alter retinal hemodynamics. This finding suggests that HGF signaling may be independent of that of VEGF, a possibility supported by the finding of no correlation between vitreous concentrations of HGF and VEGF in patients with PDR and in patients with nondiabetic ocular disease. ${ }^{28}$ We demonstrated in an earlier study that HGF's effects on retinal angiogenesis are additive with VEGF $^{26}$ and that VEGF mediates its in vivo vasopermeability effects pre- 

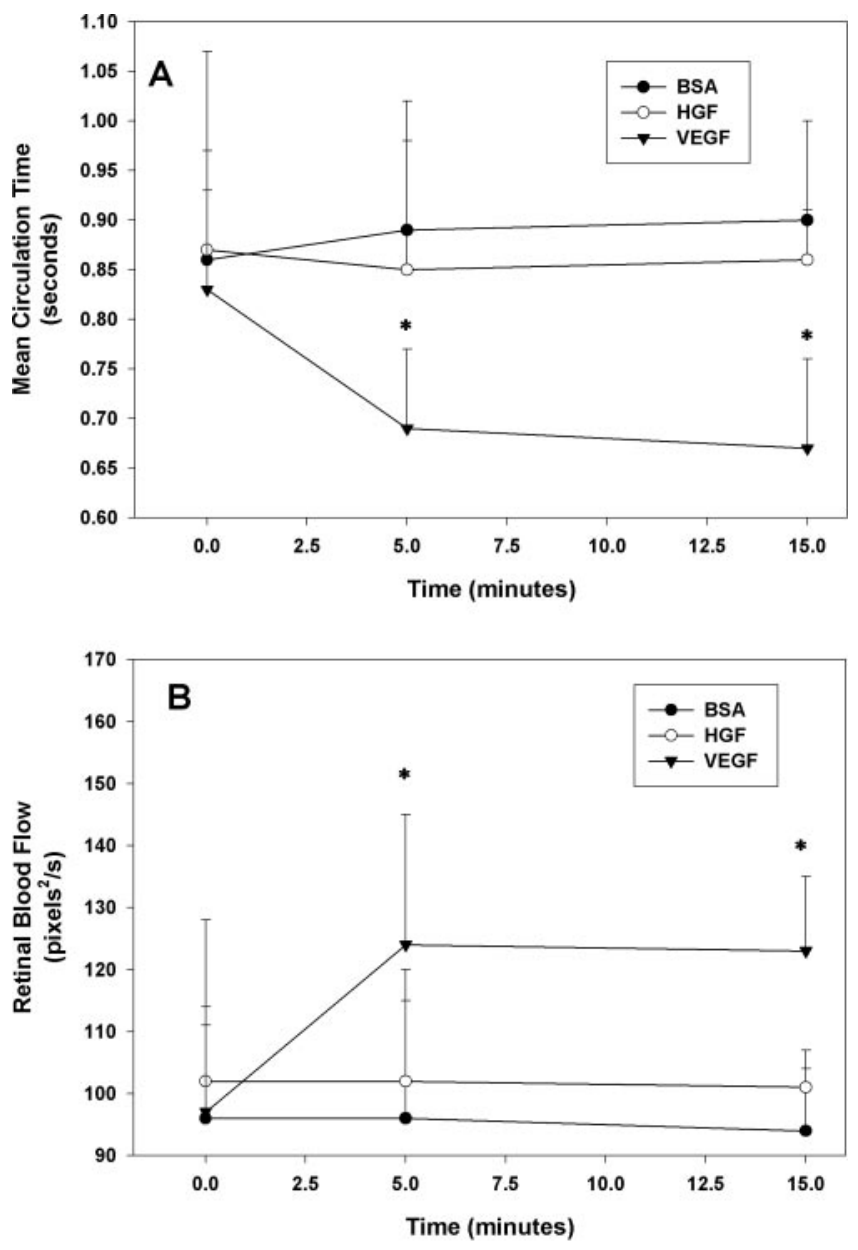

Figure 5. HGF, unlike VEGF, did not decrease mean circulation time or increase retinal blood flow. Retinal hemodynamics were assessed by video fluorescein angiography at baseline and after intravitreal injection of HGF ( $5 \mathrm{ng} /$ eye), VEGF ( $2 \mathrm{ng} /$ eye), or vehicle alone (0.1\% BSA). MCT (A) was reduced and RBF (B) was increased at 5 and 15 minutes $(P<0.05)$ after intravitreal injection of VEGF. No change was observed with HGF or vehicle compared with baseline.

dominantly through the $\beta$ isoform of PKC and the high-affinity kinase insert domain-containing receptor (KDR). ${ }^{3}$ HGF mediates its effects through the cell surface tyrosine kinase receptor encoded by the c-MET proto-oncogene, ${ }^{11,12}$ thought to be linked with downstream mediators by the effector protein Grb2. ${ }^{32}$ However, despite independent pathways, HGF and VEGF together did not exert an additive effect on vasopermeability in vivo. Because treatment with inhibitors suppressed combined HGF/VEGF leakage by only $30 \%$ compared with a $90 \%$ suppression when treated with HGF alone, it is possible that VEGF continues to induce permeability at these concentrations, perhaps through activation of PKC. ${ }^{3}$

$\mathrm{HGF} / \mathrm{SF}$ is a potent mitogenic and angiogenic factor that is associated with many types of cancer. One of the biological effects of HGF is to promote the matrix invasion of tumor cells by disruption of cell-cell tight junctions. HGF expression by malignant gliomas increases blood-brain barrier permeability. ${ }^{43}$ In the eye, this effect would impair the integrity of the blood-retina barrier and contribute to the accumulation of plasma proteins in the surrounding matrix. The main signaltransduction pathways by which HGF/c-MET exerts its effects are the PI-3 kinase pathway, associated with cellular migration, and the Grb2/SOS/MAPK pathway, associated with proliferation. In bovine retinal endothelial cells in vitro, we have dem- onstrated that HGF induces both MAPK phosphorylation and an increase in PI-3 kinase activity where MAPK phosphorylation was partially mediated by PI-3 kinase and to a lesser extent PKC.

In the present study, PI-3 kinase inhibition suppressed HGFinduced retinal permeability by $97 \% \pm 59 \%(P=0.021)$ without affecting basal activity. Thus, the increase in retinal permeability by HGF may be through the PI-3 kinase pathway with downstream activation of PKB/AKT and nitric oxide (NO). Okano et al. ${ }^{44}$ demonstrated that the proliferative action of HGF is predominantly mediated through activation of PI-3 kinase and AKT in rat oval cells. Furthermore, stimulation of aortic endothelial cells with HGF leads to a PI-3-kinase/AKTdependent phosphorylation of endothelial nitric oxide synthase (eNOS) within 5 minutes that would result in enzyme activation and NO production. ${ }^{45}$ Shen et al. ${ }^{46}$ found that HGF increases eNOS protein levels in adrenal capillary endothelial cells by the same extent as VEGF. The production of NO could activate the cyclic GMP/cyclic GMP-dependent kinase (PKG) pathway that can regulate intercellular junctional proteins. ${ }^{47}$ Also a direct effect of NO on retinal permeability was demonstrated by the dose-dependent increase in vivo on retinal vascular permeability by the NO donor $S$-nitroso- $N$-acetylpenicillamine (SNAP) (Bursell S-E, et al. IOVS 1997;38:ARVO Abstract 1135). Although mechanistic studies based on inhibitors are not conclusive, our data showing marked inhibition of HGFinduced retinal permeability by inhibition of PI-3 kinase is consistent with these data, as it would effectively block the $\mathrm{PKB} / \mathrm{AKT} / \mathrm{NO}$ signaling cascade.

On receptor binding, HGF initiates the phosphorylation of MAPK through the Grb2/SOS/ras/raf pathway. Specifically, HGF binding phosphorylates both p44/p42 (ERK1/2) and p38 MAPKs. Experimental evidence suggests that HGF-induced MAPK activation initiates cell motility by targeting adherens junctions. Although the specific target proteins for HGF-induced junctional disruption have not been fully identified, the inhibition of ERK1/2 in ras-transformed MDCK cells leads to recruitment of the adherens proteins occludin, claudin- 1 , and ZO-1. ${ }^{48}$ In the present study, HGF caused a rapid $(<15$ minutes) increase in RVP that was suppressed $86 \% \pm 44 \%(P=$ $0.015)$ by inhibition of MAPK in vivo, suggesting that HGF is modulating RVP through a rapid signaling mechanism rather than junctional protein synthesis.

In contrast to the effect of HGF on retinal vascular leakage presented in the present study, other data have suggested that HGF can enhance endothelial cell barrier function and may tighten cell junctions. ${ }^{34}$ In a study by Liu et al., ${ }^{34}$ transendothelial resistance of EC monolayers was increased after treatment with HGF. However, these results are in contrast to the HGF-induced increase in paracellular leakage observed by Jiang et al. ${ }^{18}$ The opposing conclusions may arise due to differences in cell lines and the fact that in vitro EC monolayers may not correspond directly to responses in whole tissues in vivo. Microvascular endothelial cells require contact with vascular smooth muscle cells and pericytes for proper cellular communication and may respond differently compared with the arterial endothelial cells used in the study by Liu et al. Specifically, the activation PI-3 kinase has been linked to phosphorylation of AKT and eNOS which are thought to be associated with an enhancement in paracellular leakage. ${ }^{49}$ Indeed, Shen et al. ${ }^{46}$ demonstrated that treatment of capillary endothelial cells with HGF increases eNOS protein expression by the same magnitude as VEGF.

Inhibition of PKC using the non-isoform-specific GFX (0.5 $\mu \mathrm{M}$ ) did not significantly suppress HGF-induced RVP. This is in contrast to another potent permeability agent, histamine, which activates PKC isoforms in addition to MEK and ERK, and whose action is suppressed by GFX..$^{3,50-53}$ PKC activation 
increases vascular leakage and regulates vascular tone. ${ }^{54}$ In diabetes, PKC activation occurs through the de novo synthesis of glucose and is activated locally by growth factors such as VEGF. Both diabetes-induced and receptor-mediated activation of PKC have been shown to modulate retinal vascular leakage specifically through the $\beta$ isoform ${ }^{3,42,55} \mathrm{HGF} / \mathrm{SF}$ binding to c-MET can phosphorylate PLC- $\gamma$, leading to the formation of IP3 and diacylglycerol in hepatocytes. ${ }^{56}$ The production of IP3 and DAG increases intracellular $\mathrm{Ca}^{2+}$ and activates PKC. In fact, stimulation of bovine retinal endothelial cells with HGF led to a $37 \%$ increase in PKC activity in situ within 10 minutes. ${ }^{26}$ In addition, studies by Sharma et al. ${ }^{57}$ and Kermorgant et al. ${ }^{58}$ have demonstrated that HGF activates PKC $\alpha$ and PKC $\varepsilon$. However, the activation of PKC $\alpha$ by c-MET has been associated with the recycling of c-MET receptor through intracellular microtubules and modulation of the MAPK pathway rather than direct functional control. ${ }^{26,58,59} \mathrm{HGF}$ also induces $\mathrm{PKC} \alpha$ translocation in corneal epithelial cells. ${ }^{57}$ Thus, although HGF can induce PKC activation in cells, the specific isoforms and extent of PKC activation in retinal tissue is unknown, and our data suggest that HGF can induce retinal vascular permeability predominantly independent of its effects on PKC. Also, as demonstrated by Bursell et al., ${ }^{37}$ PKC plays a prominent role in the regulation of retinal blood flow in diabetes. The lack of c-MET modulated PKC action on vascular hemodynamics is supported by our finding of no HGF-induced alterations in retinal blood flow.

In summary, this study demonstrates that HGF increases retinal vascular permeability in a time- and dose-dependent manner, resulting in ocular permeability at physiologically relevant concentrations similar to that induced by VEGF. In contrast, retinal hemodynamics remain unaltered by HGF. Effects of HGF on retinal permeability appear to be mediated by PI-3 kinase and MAPK, but not predominantly by PKC. Thus, the effects of HGF and VEGF on RVP may be mediated by different pathways, and further studies to elucidate the mechanisms by which HGF induces these effects may lead to novel therapeutic targets for ocular conditions characterized by retinal vascular leakage.

\section{References}

1. Leung DW, Cachianes G, Kuang WJ, Goeddel DV, Ferrara N. Vascular endothelial growth factor is a secreted angiogenic mitogen. Science. 1989;246:1306-1309.

2. Senger DR, Galli SJ, Dvorak AM, Perruzzi CA, Harvey VS, Dvorak JF. Tumor cells secret a vascular permeability factor that promotes accumulation of ascytes fluid. Science. 1983;219:983-985.

3. Aiello LP, Bursell S-E, Clermont AC, et al. Vascular endothelial growth factor-induced retinal permeability is mediated by protein kinase $\mathrm{C}$ in vivo and suppressed by an orally effective $\beta$-isoformselective inhibitor. Diabetes. 1997;46:1473-1480.

4. Aiello LP, Pierce EA, Foley ED, et al. Suppression of retinal neovascularization in vivo by inhibition of vascular endothelial growth factor (VEGF) using soluble VEGF-receptor chimeric proteins. Proc Natl Acad Sci USA. 1995;92:10457-10461.

5. Funatsu H, Yamashita H, Ikeda T, Nakanishi Y, Kitano S, Hori S. Angiotensin II and vascular endothelial growth factor in the vitreous fluid of patients with diabetic macular edema and other retinal disorders. Am J Ophthalmol. 2002;133:537-543.

6. Boyd SR, Zachary I, Chakravarthy U, et al. Correlation of increased vascular endothelial growth factor with neovascularization and permeability in ischemic central vein occlusion. Arch Ophthalmol. 2002;120:1644-1650.

7. Tolentino MJ, Husain D, Theodosiadis P, et al. Angiography of fluoresceinated anti-vascular endothelial growth factor antibody and dextrans in experimental choroidal neovascularization. Arch Ophthalmol. 2000;118:78-84.

8. Miyamoto K, Khosrof S, Bursell SE, et al. Vascular endothelial growth factor (VEGF)-induced retinal vascular permeability is me- diated by intercellular adhesion molecule-1 (ICAM-1). Am J Pathol. 2000;156:1733-1739.

9. Stoker M, Gherardi E, Perryman M, Gray J. Scatter factor is a fibroblast-derived modulator of epithelial cell mobility. Nature. 1987;327:239-242.

10. Weidner KM, Behrens J, Vandekerckhove J, Birchmeier W. Scatter factor molecular characteristics and effect on the invasiveness of epithelial cells. J Cell Biol. 1990;111:2097-2108.

11. Naldini L. Vigna E, Narsimhan RP, et al. Hepatocyte growth factor (HGF) stimulates the tyrosine kinase activity of the receptor encoded by the proto-oncogene c-MET. Oncogene. 1991;6:501-504.

12. Galimi F, Brizzi MF, Comoglio PM. The hepatocyte growth factor and its receptor. Stem Cells. 1993;11:22-30.

13. Crepaldi T, Pollack AL, Prat M, et al. Targeting of the SH/HGF receptor to the basolateral domain of polarized epithelial-cells. J Cell Biol. 1994;125:313-320.

14. Bardelli A, Longati $P$, Williams TA, et al. A peptide representing the carboxyl-terminal tail of the met receptor inhibits kinase activity and invasive growth. J Biol Chem. 1999;274:29274-29281.

15. Gherardi E, Gray J, Stoker M, Perryman M, Furlong R. Purification of scatter factor, a fibroblast-derived basic protein that modulates epithelial interactions and movement. Proc Natl Acad Sci USA. 1989;86:5844-5848.

16. Gherardi E, Sharpe M, Lane K, Sirulnik A, Stoker M. Hepatocyte growth factor/scatter factor (HGF/SF), the c-met receptor and the behavior of epithelial cells. Symp Soc Exp Biol. 1993;47:163-181.

17. Martin TA, Watkins G, Mansel RE, Jiang WG. Hepatocyte growth factor disrupts tight junctions in human breast cancer cells. Cell Biol Int. 2004;28:361-371.

18. Jiang WG, Martin TA, Matsumoto K, Nakamura T, Mansel RE. Hepatocyte growth factor/scatter factor decreases the expression of occluding and transendothelial resistance (TER) and increases paracellular permeability in human vascular endothelial cells. J Cell Physiol. 1999;181:319-329.

19. Martin TA, Mansel R, Jiang WG. Hepatocyte growth factor modulates vascular endothelial cadherin expression in human endothelial cells. Clin Cancer Res. 2001;7:734-737.

20. Lipschutz JH, Li S, Arisco A, Balkovetz DF. Extracellular-signalregulated kinases 1/2 control claudin-2 expression in Madin-Darby canine kidney strain I and II cells. J Biol Chem. 2005;;280:37803788.

21. Davies G, Jiang WG, Mason MD. HGF/SF modifies the interaction between its receptor c-Met, and the E-cadherin/catenin complex in prostate cancer cells. Int J Mod Med. 2001;7:385-388.

22. Hiscox S, Jiang WG. Hepatocyte growth factor/scatter factor disrupts epithelial tumour cell-cell adhesion: involvement of betacatenin. Anticancer Res. 1999;19:509-517.

23. Grant DS, Kleinman HK, Goldberg ID, et al. Scatter factor induces blood vessel formation in vivo. Proc Natl Acad Sci USA. 1993;90: 1937-1941.

24. Bussolino F, DiRenzo MF, Ziche M, et al. Hepatocyte growth factor is a potent angiogenic factor which stimulates endothelial cell motility and growth. J Cell Biol. 1992;119:629-641.

25. He PM, He S, Garner JA, Ryan SJ, Hinton DR. Retinal pigment epithelial cells secrete and respond to hepatocyte growth factor. Biochem Biophys Res Commun. 1998;249:253-257.

26. Cai W, Rook SL, Jiang ZY, Takahara N, Aiello LP. Mechanisms of hepatocyte growth factor-induced retinal endothelial cell migration and growth. Invest Ophthalmol Vis Sci. 2000;41:1885-1893.

27. Vasir B, Reitz P, Xu G, Sharma A, Bonner-Weir S, Weir GC. Effects of diabetes and hypoxia on gene markers of angiogenesis (HGF, cMET, UPA and UPAR, TGF-alpha, TGF-beta, bFGF and vimentin) in cultured and transplanted rat islets. Diabetologia. 2000;43:763772 .

28. Katsura Y, Okano T, Noritake M, et al. Hepatocyte growth factor in vitreous fluid of patients with proliferative diabetic retinopathy and other retinal disorders. Diabetes Care. 1998;21:1759-1763.

29. Nishimura $M$, Ikeda $T$, Ushiyama $M$, et al. Increased vitreous concentrations of human hepatocyte growth factor in proliferative diabetic retinopathy. J Clin Endocrinol Metab. 1999;84:659-662.

30. Gille J, Khalik M, Konig V, Kaufmann R. Hepatocyte growth factor/ scatter factor (HGF/SF) induces vascular permeability factor (VPF/ 
VEGF) expression by cultured keratinocytes. J Invest Dermatol. 1998; 111:1160-1165.

31. Lashkari K, Rahimi N, Kazlauskas A. Hepatocyte growth factor receptor in human RPE cells: implications in proliferative vitreoretinopathy. Invest Ophthalmol Vis Sci. 1999;40:149-156.

32. Atabey N, Gao Y, Yao ZJ, et al. Potent blockade of hepatocyte growth factor-stimulated cell motility, matrix invasion and branching morphogenesis by antagonists of Grb2 Src homology 2 domain interactions. J Biol Chem. 2001;276:14308-14314.

33. Wojciank-Stothard B, Ridley AJ. Rho GTPases and the regulation of endothelial permeability. Vascul Pharmacol. 2002;39:187-199.

34. Liu F, Schaphorst KL, Verin AD, et al. Hepatocyte growth factor enhances endothelial cell barrier function and cortical cytoskeletal rearrangement: potential role of glycogen synthase kinase-3beta. FASEB J. 2002;16:950-962.

35. Hughes A. A schematic eye for the rat. Vision Res. 1978;19:569588.

36. Abiko T, Abiko A, Clermont AC, et al. Characterization of retinal leukostasis and hemodynamics in insulin resistance and diabetes: role of oxidants and protein kinase-C activation. Diabetes. 2003; 52:829-837.

37. Bursell S-E, Takagi C, Clermont AC, et al. Specific retinal diacyclglycerol and protein kinase $\mathrm{C}$ beta isoform modulation mimics abnormal retinal hemodynamics in diabetic rats. Invest Ophthalmol Vis Sci. 1997;38:2711-2720.

38. Dawson DW, Volpert OV, Gillis P, et al. Pigment epitheliumderived factor: a potent inhibitor of angiogenesis. Science. 1999; 285:245-248

39. Martin TA, Mansel RE, Jiang WG. Antagonistic effect of NK4 on HGF/SF induced changes in the transendothelial resistance (TER) and paracellular permeability of human vascular endothelial cells. J Cell Phys. 2002;192:268-275.

40. Nishimura M. Nakano K, Ushiyama $M$, et al. Increased serum concentrations of human hepatocyte growth factor in proliferative diabetic retinopathy. J Clin Endocrinol Metab. 1998;83:195-199.

41. Shinoda K, Ishida S, Kawashima S, et al. Clinical factors related to the aqueous levels of vascular endothelial growth factor and hepatocyte growth factor in proliferative diabetic retinopathy. Curr Eye Res. 2000;21:655-661.

42. Clermont AC, Aiello LP, Mori F, Aiello LM, Bursell S-E. Vascular endothelial growth factor and severity of nonproliferative diabetic retinopathy mediate retinal hemodynamics in vivo: a potential role for vascular endothelial growth factor in the progression of nonproliferative diabetic retinopathy. Am J Ophthalmol. 1997;124: 433- 446.

43. Book A, Ranganathan S, Abounader R, et al. Scatter factor/hepatocyte growth factor gene transfer increases rat blood-glioma barrier permeability. Brain Res. 1999;833:173-180.

44. Okano J, Shiota G, Matsumoto K, et al. Hepatocyte growth factor exerts a proliferative effect on oval cells through the PI3K/AKT signaling pathway. Biochem Biophys Res Commun. 2003;309: 298-304.

45. Makondo K, Kimura K, Kitamura N, et al. Hepatocyte growth factor activates endothelial nitric oxide synthase by $\mathrm{Ca} 2+$ - and phosphoinositide 3-kinase/Akt-dependent phosphorylation in aortic endothelial cells. Biochem J. 2003;374:63-69.

46. Shen BQ, Lee DY, Zioncheck TF. Vascular endothelial growth factor governs endothelial nitric oxide synthase expression via a KDR/Flk-1 receptor and a protein kinase $C$ signaling pathway. J Biol Chem. 1999;274:33057-33063.

47. Huang Q, Yuan Y. Interaction of PKC and NOS in signal transduction of microvascular hyperpermeability. Am J Physiol. 1997;273: $\mathrm{H} 2442-\mathrm{H} 2451$.

48. Chen Y, Qun L, Schneeberger EE, Goodenough DA. Restoration of tight junction structure and barrier function by down-regulation of the mitogen-activated protein kinase pathway in ras-transformed madin-darby canine kidney cells. Mol Biol Cell. 2000;11:849-862.

49. Lal BK, Varma S, Pappas PJ, Hobson RW, Duran WN. VEGF increases permeability of the endothelial cell monolayer by activation of PKB/akt, endothelial nitric-oxide synthase, and MAP kinase pathways. Microvasc Res. 2001;62:252-262.

50. Singer HA, Schworer CM, Sweeley C, Benscoter H. Activation of protein kinase $\mathrm{C}$ isozymes by contractile stimuli in arterial smooth muscle. Arch Biochem Biophys. 1992;299:320-329.

51. Jeong JH, Yun MC, Shin CY, Lee TS, Song HJ, Sohn UD. Signaling via histamine receptors in cat duodenal smooth muscle cells. Mol Cells. 2003;31:180-186.

52. Matsubara M, Tamura T, Ohmori K, Hasegawa K. Histamine H1 receptor antagonist blocks histamine-induced proinflammatory cytokine production through inhibition of $\mathrm{Ca} 2+$-dependent protein kinase C, Raf/MEK/ERK and IKK/I kappa B/NF-kappa B signal cascades. Biochem Pharmacol. 2005;69:433-449.

53. Wu MH, Yuan SY, Granger HJ. The protein kinase MEK1/2 mediate vascular endothelial growth factor- and histamine induced hyperpermeability in porcine coronary venules. J Physiol. 2005;563:95104.

54. Lynch JJ, Ferro TJ, Blumenstock FA, et al. Increased endothelial albumin permeability mediated by protein kinase C activation. J Clin Invest. 1990;85:1991-1998.

55. Shiba T, Inoguchi T, Sportsman JR, Heath WF, Bursell SE, King GL. Correlation of diacylglycerol level and protein kinase C activity in rat retina to retinal circulation. Am J Physiol. 1993;265:E783E793.

56. Okano Y, Mizuno K, Osada S, Nakamura T, Nozawa Y. Tyrosine phosphorylation of phospholipase C gamma in c-met/HGF receptor-stimulated hepatocytes: comparison with HepG2 hepatocarcinoma cells. Biochem Biophys Res Commun. 1993;190:842-848.

57. Sharma GD, Ottino P, Bazan NG, Bazan HE. Epidermal and hepatocyte growth factors, but not keratinocyte growth factor, modulate protein kinase Calpha translocation to the plasma membrane through 15(S)-hydroxyeicosatetraenoic acid synthesis. J Biol Chem. 2005;280:7917-7924.

58. Kermorgant S, Zicha D, Parker PJ. PKC controls HGF-dependent c-MET traffic, signaling and cell migration. EMBOJ. 2004;23:3721334 .

59. Kermorgant S, Zicha D, Parker PJ. Protein kinase C controls microtubule-based traffic but not proteasomal degradation of c-Met. J Biol Chem. 2003;278:28921-28929. 